\title{
Kajian Ketelitian Current Transformer (CT) Terhadap Kesalahan Rasio Arus pada Pelanggan 197 kVA
}

\author{
Tony Koerniawan ${ }^{1}$; Aas Wasri Hasanah ${ }^{2}$; Yuliansyah ${ }^{3}$ \\ 1, 2, ${ }^{3}$ Teknik Elektro, Sekolah Tinggi Teknik PLN \\ 'tonykoerniawan84@gmail.com
}

\begin{abstract}
With the growth of electricity consumption getting bigger, the possibility of greater losses arises from measuring energy in customers. One cause of the losses due to mistakes in flow ratio CT (Current Transformer) installed on APP Box indirect measurement. Necessary to test the CT accuracy class to determine the current ratio error limits set by the standard PLN. Then do the replacement on the CT accuracy class to resolve this issue. This activity is done at the customer PT. Astra Int Auto 2000 by replacing the CT accuracy class of 0.5 becomes 0,5S. There is a comparison of the measurement between the two different classes. Based on the results of tests performed, a decline in the current ratio error before and after the replacement of accuracy class. After calculating the error margin of the second flow ratio CT installed that are not measured by the energy meter. This Value $k W h$ that is the losses to PT. PLN (Persero) Area Depok. So understanding $C T$ as one of the tools of measurement (instrumentation) should be changed to a point of transaction (point of transaction). So that the revenue gains $k W h$ a business orientation that is fundamental to PLN by pressing slightly possible energy losses (losses) that occur in the measurement system.
\end{abstract}

Keywords: CT, Error Flow Ratio, Accuracy Class, Losses

\begin{abstract}
ABSTRAK
Dengan pertumbuhan konsumsi energi listrik yang semakin besar, maka kemungkinan semakin besar kerugian yang timbul akibat pengukuran energi pada pelanggan. Salah satu penyebab timbulnya kerugian karena adanya kesalahan rasio arus CT (Current Transformer) yang terpasang pada Kotak APP pengukuran tidak langsung. Perlu dilakukan pengujian kelas ketelitian pada CT untuk mengetahui batas kesalahan rasio arus yang diatur oleh standar PLN. Kemudian dilakukan penggantian kelas ketelitian pada CT untuk mengatasi masalah ini. Kegiatan ini dilakukan pada pelanggan PT. Astra Int Auto 2000 dengan mengganti kelas ketelitian CT dari 0,5 menjadi 0,5S. Terjadi perbandingan pengukuran antara kedua kelas yang berbeda. Maka pemahaman. Setelah dilakukan perhitungan selisih kesalahan rasio arus dari kedua CT yang terpasang bahwa terdapat energi yang tidak terukur oleh $\mathrm{kWh}$ meter. Besar nilai $\mathrm{kWh}$ inilah yang menjadi rugi-rugi atau losses untuk PT. PLN (Persero) Area Depok. CT sebagai salah satu alat bantu pengukuran (instrumentation) harus dirubah menjadi sebuah titik transaksi (point of transaction). Sehingga keuntungan pendapatan $\mathrm{kWh}$ merupakan orientasi bisnis yang mendasar bagi PLN dengan menekan sedikit mungkin kerugian energi (losses) yang terjadi di sistem pengukuran tersebut.
\end{abstract}

Kata kunci: $C T$, kesalahan rasio arus, kelas ketelitian, losses 


\section{PENDAHULUAN}

Seiring besarnya pertumbuhan konsumsi energi listrik yang terus meningkat, maka potensi losses atau rugi juga akan semakin besar. Salah satu faktor yang menjadi penyebab losses adalah tidak sesuainya energi yang terukur pada kWh Meter dengan energi yang dipakai sebenarnya oleh pelanggan. Hal ini merupakan efek dari pengukuran tidak langsung. Pengukuran tidak langsung dilakukan dengan alat bantu berupa Current Transformer (CT) yang berfungsi membantu metering untuk menyesuaikan besar arus yang masuk ke kWh Meter. Kesalahan rasio arus pada $C T$ akan sangat berpengaruh pada pengukuran $\mathrm{kWh}$ Meter di konsumen. Kesalahan rasio merupakan perbandingan antara arus yang mengalir pada sisi primer $C T$ dengan arus yang terbaca pada sisi sekunder $C T$ terukur oleh alat $C T$ Analyzer. Semakin besar kesalahan rasio $C T$, maka beda pengukuran $\mathrm{kWh}$ meter dengan energi terpakai akan semakin besar.

Untuk pelanggan tegangan rendah dengan daya $197 \mathrm{kVA}$ menggunakan $C T$ yang terpasang sudah menjadi satu dengan Kotak APP Terpadu dan kelas ketelitian CT 0,5S. Penggunaan kelas ketelitian $0,5 \mathrm{~S}$ untuk mengurangi terjadinya kesalahan rasio arus pada saat pemakaian beban pelanggan rendah. Sebab kelas $0,5 \mathrm{~S}$ memiliki kesalahan rasio arus yang kecil saat pembebanan rendah $20 \%$ hingga $120 \%$. Dengan begitu kesalahan pengukuran energi yang terpakai dapat berkurang.

Dalam penelitian ini, penulis ingin membahas mengenai pengukuran kelas ketelitian pada $C T$. Pengambilan data dilakukan pada pelanggan PT. PLN (Persero) Area Depok Rayon Cibinong yaitu PT. Astra Int Auto 2000. Pengukuran dilakukan untuk mengetahui batas kesalahan rasio arus yang diatur oleh standar PLN. Besar kesalahan rasio arus ini akan menjadi rugi-rugi atau losses untuk perusahaan yang akan menimbulkan kerugian energi. Sehingga tingkat kelas ketelitian CT perlu diperhatikan untuk menekan kerugian dalam transaksi energi.

\subsection{Trafo Arus/Current Transformer (CT)}

Trafo Arus (Current Transformer-CT) yaitu peralatan yang digunakan untuk melakukan pengukuran besaran arus pada intalasi tenaga listrik di sisi primer (TET, TT dan TM) yang berskala besar dengan menurunkan arus secara akurat dan teliti untuk keperluan pengukuran dan proteksi.

\subsection{Fungsi Trafo Arus}

Secara umum, trafo arus berfungsi untuk:

1. Mengkonversi besaran arus pada sistem tenaga listrik dari besaran primer menjadi besaran sekunder untuk keperluan pengukuran sistem metering dan proteksi.

2. Mengisolasi rangkaian sekunder terhadap rangkaian primer, sebagai pengamanan terhadap manusia atau operator yang melakukan pengukuran.

\section{METODE PENELITIAN}

\subsection{Daya aktif Pelanggan}

Seperti diketahui bahwa daya aktif untuk pelanggan PT. ASTRA INT AUTO 2000 bila diketahui besar daya semunya dapat dirumuskan sebagai berikut:

$$
\mathrm{P}=\mathrm{S} \times \operatorname{Cos} \varphi
$$

Dimana:

$\mathrm{P}=$ Daya aktif trafo $(\mathrm{kW})$

$\mathrm{S}=$ Daya semu trafo $(\mathrm{kVA})$

Setelah didapat daya aktif yang diterima pelanggan PT. ASTRA INT AUTO 2000, maka persentase pemakaian beban pada pelanggan tersebut dapat diketahui sebagai berikut: 


$$
\% \text { pemakaian beban }=\frac{\text { Rata }- \text { rata } \text { Pemakaian }}{\text { Daya Maksimal }} \times 100 \%
$$

Besarnya nilai rasio $C T$ terpasang sesuai dengan dayakontrak pelanggan pada beban penuh dapat dihitung dengan menentukan nilai arus primer sebagai berikut:

$$
I_{p}=\frac{\text { Daya Kontrak }}{\text { Tegangan } x \sqrt{3}}
$$

\subsection{Perhitungan Selisih Transformasi Arus pada $C T$}

Untuk mengetahui besar arus yang telah ditransformasikan $C T$ di sisi primer dan sekunder pada pengukuran tak langsung pelanggan PT. ASTRA INT AUTO 2000 dapat menggunakan persamaan sebagai berikut:

$$
\begin{array}{ll}
\mathrm{I}_{\mathbf{p} \text { sebenarnya }} & =\text { persentase pemakaian beban } \times \mathbf{I}_{\mathbf{p}} \\
\mathrm{I}_{\mathrm{s} \text { sebenarnya }} & =\text { persentase pemakaian beban } \times \mathbf{I}_{\mathbf{s}}
\end{array}
$$

\subsection{Perhitungan Kesalahan Rasio Arus}

Setelah mendapatkan selisih dari arus yang ditransformasikan oleh $C T$ pada pelanggan PT. ASTRA INT AUTO 2000 serta melihat besaran pembebanan pada pelanggan dapat dihitung dengan persamaan:

$$
\% \text { Kesalahan Rasio Arus }=\frac{\left(K_{n} \times I_{S \text { kenyataan }}-I_{p}\right) \times 100}{I p}
$$

Dimana:

$\mathrm{K}_{\mathrm{n}} \quad=$ Pengenal rasio arus trafo

$\mathrm{I}_{\mathrm{s} \text { kenyataan }}=$ Arus aktual pada sisi sekunder trafo $(\mathrm{A})$

$\mathrm{I}_{\mathrm{p}} \quad=$ Arus sebenarnya pada sisi primer trafo (A

\subsection{Rugi Energi Tidak Terukur}

Akibat kesalahan rasio arus pada alat ukur yang dimiliki maka timbul perbedaan nilai pemakaian energi di pelanggan. Sehingga menimbulkan kerugian secara teknis dan dapat dihitung dengan persamaan sebagai berikut:

Kerugian Energi $=\sqrt{3} \times$ V x Selisih Arus Primer $x \operatorname{Cos} \varphi \times 24$ jam x 30 hari 


\subsection{Diagram Alir Penelitian}

Berikut adalah diagram alir penelitian yang dilakukan:

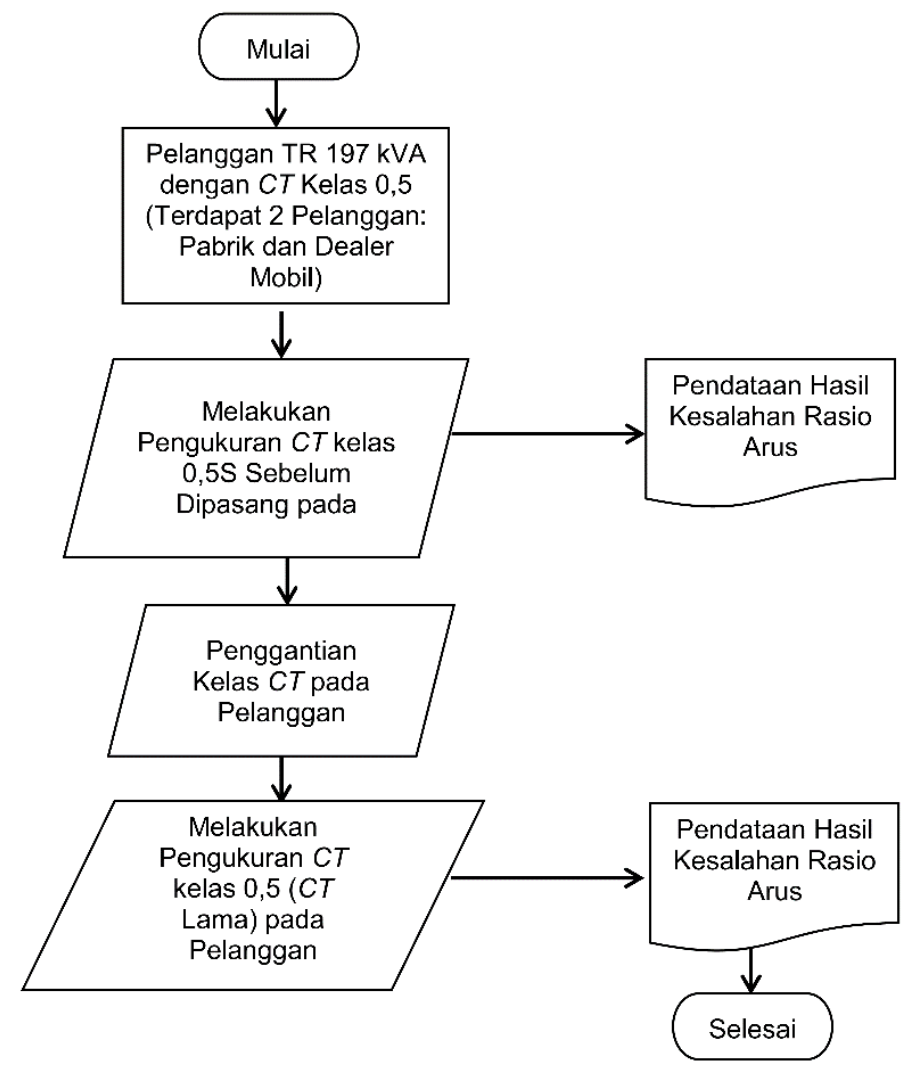

Gambar 1. Diagram Alir Penelitian

\section{HASIL DAN PEMBAHASAN}

\subsection{Gambaran Umum}

Pada penelitian ini, untuk melakukan perbandingan kelas klasifikasi Current Transformer $(C T)$ dilakukan pengambilan data pada pelanggan PT. Astra Int Auto 2000 dengan nama gardu OTO sesuai data tabel 2 di bawah:

Tabel 1. Data Pelanggan

\begin{tabular}{|c|c|}
\hline Nama Pelanggan & PT. ASTRA INT AUTO 2000 \\
\hline No. ID Pelanggan & 538720764150 \\
\hline Nama Gardu & OTO \\
\hline Alamat & Jalan Raya Bogor No. 28, Pabuaran, Cibinong, Bogor \\
\hline $\begin{array}{c}\text { Daya dan Golongan } \\
\text { Tarif }\end{array}$ & 197 kVA dan Tarif B2 Golongan 0 \\
\hline
\end{tabular}

\subsection{Perhitungan Rasio CT TR}

Pada penelitian ini, untuk melakukan perbandingan kelas klasifikasi Current Transformer (CT) dilakukan pengambilan data pada pelanggan PT. Astra Int Auto 2000 dengan nama gardu OTO sesuai data tabel 2 di bawah:

Dengan perhitungan ini, dapat diketahui besarnya nilai rasio yang sesuai dengan daya kontrak pelanggan yaitu $197 \mathrm{kVA}$. Maka pada beban penuh nilai rasionya adalah: 


$$
\begin{gathered}
I_{p}=\frac{\text { Daya Kontrak }}{\text { Tegangan } x \sqrt{3}} \\
I_{p}=\frac{197000 \mathrm{VA}}{400 \mathrm{~A} x \sqrt{3}} \\
I_{p}=284,35 \mathrm{~A} \approx 300 \mathrm{~A}
\end{gathered}
$$

Setelah diketahui arus primer yaitu $300 \mathrm{~A}$, dan untuk arus sekunder bernilai $5 \mathrm{~A}$ karena $\mathrm{kWh}$ Meter yang terpasang pada Kotak APP hanya memiliki kemampuan input 5 A, yang artinya bila di sisi primer dialiri 300 A maka pada sisi sekunder akan mengeluarkan output sebesar $5 \mathrm{~A}$.

\begin{tabular}{|c|c|c|c|}
\hline \multirow[b]{2}{*}{ Fasa } & \multicolumn{2}{|c|}{ Hasil Pengujian } & \multirow[b]{2}{*}{$\mathbf{F K}^{*}$} \\
\hline & $\begin{array}{c}\text { Arus Pengenal/ } \\
\text { Inject }(\%)\end{array}$ & $\begin{array}{c}\text { Kesalahan } \\
\text { Rasio Arus (\%) }\end{array}$ & \\
\hline \multirow{4}{*}{$\begin{array}{c}\mathbf{R} \\
(\mathbf{L} 1)\end{array}$} & 1 & $-0,92$ & 1,009 \\
\hline & 5 & $-0,93$ & 1,009 \\
\hline & 10 & $-0,79$ & 1,008 \\
\hline & 20 & $-0,72$ & 1,007 \\
\hline \multirow{3}{*}{$\begin{array}{c}\text { No. Seri } \\
1609144513\end{array}$} & 50 & $-0,62$ & 1,006 \\
\hline & 100 & $-0,40$ & 1,004 \\
\hline & 120 & $-0,52$ & 1,005 \\
\hline \multirow{4}{*}{$\begin{array}{c}\mathrm{S} \\
(\mathbf{L} 2)\end{array}$} & 1 & $-1,38$ & 1,013 \\
\hline & 5 & $-0,90$ & 1,009 \\
\hline & 10 & $-0,88$ & 1,009 \\
\hline & 20 & $-0,80$ & 1,008 \\
\hline \multirow{3}{*}{$\begin{array}{c}\text { No. Seri } \\
1609144514\end{array}$} & 50 & $-0,66$ & 1,007 \\
\hline & 100 & $-0,37$ & 1,004 \\
\hline & 120 & $-0,39$ & 1,004 \\
\hline \multirow{4}{*}{$\begin{array}{c}\mathbf{T} \\
(\mathbf{L} 3)\end{array}$} & 1 & $-1,80$ & 1,018 \\
\hline & 5 & $-1,02$ & 1,010 \\
\hline & 10 & $-0,86$ & 1,009 \\
\hline & 20 & $-0,78$ & 1,008 \\
\hline \multirow{3}{*}{$\begin{array}{c}\text { No. Seri } \\
1609144515\end{array}$} & 50 & $-0,68$ & 1,007 \\
\hline & 100 & $-0,44$ & 1,004 \\
\hline & 120 & $-0,46$ & 1,005 \\
\hline
\end{tabular}

Di bawah ini adalah hasil uji dari dua kelas ketelitian $C T$ :

Tabel 2. Data Pengujian $C T$ Kelas 0,5 
Tabel 3. Data Pengujian $C T$ Kelas $0,5 \mathrm{~S}$

\begin{tabular}{|c|c|c|c|}
\hline \multirow[b]{2}{*}{ Fasa } & \multicolumn{2}{|c|}{ Hasil Pengujian } & \multirow[b]{2}{*}{$\mathbf{F K}^{*}$} \\
\hline & $\begin{array}{c}\text { Arus } \\
\text { Pengenal/ } \\
\text { Inject }(\%)\end{array}$ & $\begin{array}{c}\text { Kesalahan } \\
\text { Rasio Arus (\%) }\end{array}$ & \\
\hline \multirow{4}{*}{$\begin{array}{c}\mathbf{R} \\
(\mathbf{L} 1)\end{array}$} & 1 & $-0,99$ & 1,010 \\
\hline & 5 & $-0,70$ & 1,007 \\
\hline & 10 & $-0,65$ & 1,007 \\
\hline & 20 & $-0,43$ & 1,004 \\
\hline \multirow{3}{*}{$\begin{array}{c}\text { No. Seri } \\
\text { 21/09/05.5292 }\end{array}$} & 50 & $-0,37$ & 1,004 \\
\hline & 100 & $-0,25$ & 1,003 \\
\hline & 120 & $-0,16$ & 1,002 \\
\hline \multirow{4}{*}{$\begin{array}{c}\mathbf{S} \\
(\mathbf{L} 2)\end{array}$} & 1 & $-1,05$ & 1,010 \\
\hline & 5 & $-0,69$ & 1,007 \\
\hline & 10 & $-0,55$ & 1,006 \\
\hline & 20 & $-0,39$ & 1,004 \\
\hline \multirow{3}{*}{$\begin{array}{c}\text { No. Seri } \\
\text { 21/08/05.0216 }\end{array}$} & 50 & $-0,32$ & 1,003 \\
\hline & 100 & $-0,23$ & 1,002 \\
\hline & 120 & $-0,15$ & 1,002 \\
\hline \multirow{4}{*}{$\begin{array}{c}\mathbf{T} \\
(\mathbf{L 3})\end{array}$} & 1 & $-0,97$ & 1,010 \\
\hline & 5 & $-0,62$ & 1,006 \\
\hline & 10 & $-0,55$ & 1,006 \\
\hline & 20 & $-0,38$ & 1,004 \\
\hline \multirow{3}{*}{$\begin{array}{c}\text { No. Seri } \\
21 / 05 / 05.3743\end{array}$} & 50 & $-0,29$ & 1,003 \\
\hline & 100 & $-0,21$ & 1,002 \\
\hline & 120 & $-0,16$ & 1,002 \\
\hline
\end{tabular}

Dimana:

*) FK (Faktor Koreksi $)=\frac{1}{\left(1+\left(\frac{\text { Kesalahan Rasio Arus }}{100}\right)\right)}$

\subsection{Selisih KWh Terukur Berdasarkan Energi Perhitungan}

Besar setiap FK perfasa dikalikan besar Wh dimana hasil tersebut adalah Wh yang seharusnya terpakai di sisi pelanggan. Karena terdapat kesalahan rasio arus, maka terjadi selisih pengukuran dan pemakaian.

Tabel 4. Hasil Perhitungan Selisih kWh yang Tidak Terukur dengan CT Kelas 0,5

\begin{tabular}{|c|c|c|c|c|c|c|}
\hline \multicolumn{7}{|c|}{ Senin, 17 September 2018} \\
\hline \multirow[b]{2}{*}{ Jam } & \multirow{2}{*}{$\begin{array}{c}\text { Wh } \\
\text { Terukur }\end{array}$} & \multicolumn{4}{|c|}{ Wh Terukur x FK = Wh Sebenarnya } & \multirow[b]{2}{*}{ Selisih Wh } \\
\hline & & $\mathbf{R}$ & $\mathbf{S}$ & $\mathbf{T}$ & $\begin{array}{c}\text { Rata-rata } 3 \\
\text { Fasa }\end{array}$ & \\
\hline 01:00:00 & 983 & 989.38 & 990.18 & 988.98 & 989.51 & 7.26 \\
\hline 02:00:00 & 969 & 975.68 & 976.46 & 975.28 & 975.81 & 7.16 \\
\hline 04:00:00 & 944 & 950.88 & 951.64 & 950.49 & 951.01 & 6.97 \\
\hline 05:00:00 & 965 & 970.62 & 971.40 & 970.22 & 970.75 & 7.12 \\
\hline 06:00:00 & 1075 & 1081.96 & 1082.84 & 1081.53 & 1082.11 & 7.94 \\
\hline
\end{tabular}


Energi dan Kelistrikan: Jurnal Ilmiah

Vol. 11, No. 1, Januari - Juni 2019, P-ISSN 1979-0783, E-ISSN 2655-5042

\begin{tabular}{|c|c|c|c|c|c|c|}
\hline \multicolumn{7}{|c|}{ Senin, 17 September 2018} \\
\hline \multirow[b]{2}{*}{ Jam } & \multirow{2}{*}{$\begin{array}{c}\text { Wh } \\
\text { Terukur }\end{array}$} & \multicolumn{4}{|c|}{ Wh Terukur $x$ FK = Wh Sebenarnya } & \multirow[b]{2}{*}{ Selisih Wh } \\
\hline & & $\mathbf{R}$ & $\mathbf{S}$ & $\mathbf{T}$ & $\begin{array}{c}\text { Rata-rata } 3 \\
\text { Fasa }\end{array}$ & \\
\hline 07:00:00 & 1161 & 1170.53 & 1171.47 & 1170.06 & 1170.68 & 8.59 \\
\hline 08:00:00 & 1382 & 1390.25 & 1390.81 & 1391.09 & 1390.72 & 9.09 \\
\hline 09:00:00 & 1465 & 1474.68 & 1475.28 & 1475.57 & 1475.18 & 9.64 \\
\hline 10:00:00 & 1572 & 1581.51 & 1582.14 & 1582.46 & 1582.04 & 10.34 \\
\hline 11:00:00 & 1558 & 1567.98 & 1568.61 & 1568.93 & 1568.51 & 10.25 \\
\hline 12:00:00 & 1544 & 1554.00 & 1554.63 & 1554.94 & 1554.53 & 10.16 \\
\hline 13:00:00 & 1599 & 1609.69 & 1610.34 & 1610.66 & 1610.23 & 10.52 \\
\hline 14:00:00 & 1498 & 1509.01 & 1508.10 & 1508.40 & 1508.50 & 10.36 \\
\hline 15:00:00 & 1556 & 1565.46 & 1566.09 & 1566.41 & 1565.99 & 10.23 \\
\hline 16:00:00 & 1494 & 1503.91 & 1504.52 & 1504.82 & 1504.42 & 9.83 \\
\hline 17:00:00 & 1471 & 1480.18 & 1480.78 & 1481.08 & 1480.68 & 9.67 \\
\hline 18:00:00 & 1608 & 1617.17 & 1617.82 & 1618.15 & 1617.71 & 10.57 \\
\hline 19:00:00 & 1570 & 1579.72 & 1580.36 & 1580.67 & 1580.25 & 10.32 \\
\hline $20: 00: 00$ & 1524 & 1532.06 & 1532.67 & 1532.98 & 1532.57 & 10.01 \\
\hline 21:00:00 & 1466 & 1474.94 & 1475.54 & 1475.83 & 1475.44 & 9.64 \\
\hline 22:00:00 & 1300 & 1306.91 & 1307.43 & 1307.70 & 1307.35 & 8.54 \\
\hline $23: 00: 00$ & 1184 & 1191.29 & 1192.25 & 1190.81 & 1191.45 & 8.74 \\
\hline 00:00:00 & 1095 & 1102.47 & 1103.36 & 1102.03 & 1102.62 & 8.09 \\
\hline
\end{tabular}

Tabel 5. Hasil Perhitungan Selisih kWh yang Tidak Terukur pada $C T$ Kelas 0,5S

\begin{tabular}{|c|c|c|c|c|c|c|}
\hline \multicolumn{7}{|c|}{ Senin, 12 November 2018} \\
\hline \multirow[b]{2}{*}{ Jam } & \multirow{2}{*}{$\begin{array}{c}\text { Wh } \\
\text { Terukur }\end{array}$} & \multicolumn{4}{|c|}{ Wh Terukur $x$ FK = Wh Sebenarnya } & \multirow[b]{2}{*}{ Selisih Wh } \\
\hline & & $\mathbf{R}$ & $\mathbf{S}$ & $\mathbf{T}$ & $\begin{array}{c}\text { Rata-rata } 3 \\
\text { Fasa }\end{array}$ & \\
\hline 01:00:00 & 1232 & 1236.54 & 1236.05 & 1234.81 & 1235.80 & 4.57 \\
\hline 02:00:00 & 1185 & 1188.97 & 1188.49 & 1187.30 & 1188.25 & 4.40 \\
\hline 03:00:00 & 1160 & 1163.21 & 1162.74 & 1161.57 & 1162.51 & 4.30 \\
\hline 04:00:00 & 1170 & 1174.55 & 1174.08 & 1172.90 & 1173.84 & 4.34 \\
\hline 05:00:00 & 1167 & 1171.27 & 1170.80 & 1169.63 & 1170.57 & 4.33 \\
\hline 06:00:00 & 1215 & 1219.18 & 1218.69 & 1217.46 & 1218.44 & 4.51 \\
\hline 07:00:00 & 1233 & 1238.32 & 1237.83 & 1236.58 & 1237.58 & 4.58 \\
\hline 08:00:00 & 1475 & 1478.55 & 1477.81 & 1477.37 & 1477.91 & 4.83 \\
\hline 09:00:00 & 1626 & 1631.24 & 1630.42 & 1629.93 & 1630.53 & 5.33 \\
\hline 10:00:00 & 1727 & 1732.40 & 1731.53 & 1731.01 & 1731.64 & 5.66 \\
\hline 11:00:00 & 1811 & 1815.74 & 1814.83 & 1814.28 & 1814.95 & 5.93 \\
\hline 12:00:00 & 1813 & 1819.66 & 1818.75 & 1818.20 & 1818.87 & 5.94 \\
\hline 13:00:00 & 1859 & 1864.42 & 1863.49 & 1862.93 & 1863.61 & 6.09 \\
\hline 14:00:00 & 1826 & 1832.31 & 1831.39 & 1830.84 & 1831.51 & 5.98 \\
\hline 15:00:00 & 1812 & 1818.21 & 1817.30 & 1816.75 & 1817.42 & 5.94 \\
\hline 16:00:00 & 1851 & 1856.21 & 1855.27 & 1854.72 & 1855.40 & 6.06 \\
\hline 17:00:00 & 1872 & 1878.28 & 1877.33 & 1876.77 & 1877.46 & 6.13 \\
\hline 18:00:00 & 1934 & 1940.91 & 1939.94 & 1939.36 & 1940.07 & 6.34 \\
\hline 19:00:00 & 1949 & 1955.79 & 1954.81 & 1954.23 & 1954.94 & 6.39 \\
\hline
\end{tabular}

Energi dan Kelistrikan: Jurnal Ilmiah | 15 


\begin{tabular}{|c|c|c|c|c|c|c|}
\hline \multicolumn{7}{|c|}{ Senin, 12 November 2018} \\
\hline \multirow[b]{2}{*}{ Jam } & \multirow{2}{*}{$\begin{array}{c}\text { Wh } \\
\text { Terukur }\end{array}$} & \multicolumn{4}{|c|}{ Wh Terukur x FK = Wh Sebenarnya } & \multirow[b]{2}{*}{ Selisih Wh } \\
\hline & & $\mathbf{R}$ & $\mathbf{S}$ & $\mathbf{T}$ & $\begin{array}{c}\text { Rata-rata } 3 \\
\text { Fasa }\end{array}$ & \\
\hline 20:00:00 & 1944 & 1950.07 & 1949.09 & 1948.50 & 1949.22 & 6.37 \\
\hline 21:00:00 & 1866 & 1870.66 & 1869.72 & 1869.16 & 1869.85 & 6.11 \\
\hline $22: 00: 00$ & 1655 & 1660.18 & 1659.35 & 1658.85 & 1659.46 & 5.42 \\
\hline 23:00:00 & 1572 & 1577.07 & 1576.28 & 1575.80 & 1576.38 & 5.15 \\
\hline 00:00:00 & 1514 & 1518.18 & 1517.41 & 1516.96 & 1517.52 & 4.96 \\
\hline
\end{tabular}

Dari data-data diatas dapat disimpulkan bahwa $\mathrm{kWh}$ yang tidak terukur pada pelanggan dengan $C T$ kelas 0,5 lebih banyak daripada $0,5 \mathrm{~S}$. Energi yang tidak terukur ini akan menyebabkan kerugian biaya pada perusahaan, maka untuk mengurangi kerugian digunakan $C T$ dengan kelas ketelitian yang lebih kecil dan teliti.

\section{KESIMPULAN}

Dari hasil dan pembahasan, maka kesimpulan yang didapat dari penelitian ini, yaitu:

1. Berdasarkan pengujian $C T$ pada pelanggan PT. ASTRA INT AUTO 2000 bahwa nilai kesalahan rasio arus yang terjadi pada $C T$ kelas 0.5 lebih besar dibandingkan $C T$ kelas $0.5 \mathrm{~S}$ dan batas kelas ketelitian untuk $C T$ kelas 0,5 adalah bernilai $\pm 0,5 \%$ saat beban arus sebesar $100 \%$ sampai $120 \%$ dan pada $C T$ kelas $0,5 \mathrm{~S}$ bernilai $\pm 0,5 \%$ saat beban arus sebesar $20 \%$ sampai $120 \%$. Hal ini menunjukkan $C T$ yang dipakai pelanggan sesuai dengan standar PLN.

2. Setelah dilakukan perhitungan dalam satu minggu sebelum dan sesudah penggantian ketelitian $C T$, pada pelanggan PT. ASTRA INT AUTO 2000 terjadi selisih energi yang tidak terukur pada kWh Meter saat menggunakan $C T$ kelas 0,5 dan 0,5S, yaitu selisih energi tak terukur pada kelas $0,5 \mathrm{~S}$ lebih sedikit dari kelas 0,5 .

\section{UCAPAN TERIMA KASIH}

Penulis mengucapkan terima kasih kepada PT. PLN (Persero) Area Depok Rayon Cibinong yaitu PT. Astra Int Auto 2000. yang telah memberi dukungan yang membantu pelaksanaan penelitian dan atau penulisan artikel.

\section{DAFTAR PUSTAKA}

[1] GAE Website Home http://www.gae.co.id/

[2] Paath A, Maurits. Manfaat Penggantian CT Kelas 0,5 Dengan Kelas CT 0,5 S Di Pelanggan Besar Pada Pemakaian Beban Rendah. Indonesia: Jayapura

[3] PT. PLN (Persero). Buku 1: Kriteria Disain Enjinering Konstruksi Jaringan Disribusi Tenaga Listrik. Indonesia: Jakarta, 2010.

[4] PT. PLN (Persero). Buku 4: Standar Konstruksi Gardu Distribusi dan Gardu Hubung Tenaga Listrik. Indonesia: Jakarta, 2010.

[5] PT. PLN (Persero). Buku Pedoman Pemeliharaan Trafo Arus, 2014.

[6] Sarimun, Wahyudi. Buku Saku Pelayanan Teknik Edisi Ketiga. Depok: Garamond, 2014.

[7] SPLN D3.014-1. Trafo Instrument Untuk Sistem Distribusi (Trafo Arus), 2009.

[8] SPLN D3.015-2. Alat Pengukur, Pembatas Dan Perlengkapannya (APP TR Pengukuran Tidak Langsung Fasa Tiga untuk Pelanggan 53 kVA s/d 197 kVA), 2012. 